\title{
Serco penalised by $£ 81000$ a month over failings in Suffolk contract
}

In this News story by Jane Deith (BMJ 2014;348:g1167, doi:10. 1136/bmj.g1167), Wendy Tankard, chief contracts officer for the NHS Ipswich and East Suffolk Clinical Commissioning Group and NHS West Suffolk Clinical Commissioning Group, was quoted incorrectly.

She was quoted as saying, "Serco has failed to agree a remedial action plan to improve the community equipment service." This quote should have read: "Remedial action plans have been jointly created to address two of the three open contract queries [with Serco]. A remedial action plan will soon be agreed for the third open contract query for the community equipment service."
Wendy Tankard was also wrongly quoted as saying: "The honeymoon period [with Serco] is over." That remark should have been attributed to Graham Leaf, vice chairman of Ipswich and East Suffolk Clinical Commissioning Group, who made the comment at a meeting of the group in November. We apologise for these errors.

Cite this as: BMJ 2014;348:g1282

๑ $\mathrm{BMJ}$ Publishing Group Ltd 2014 